\title{
Dual Wideband Printed Monopole Antenna for WLAN/WiMAX Applications
}

\author{
Chien-Yuan Pan, Tzyy-Sheng Horng, Senior Member, IEEE, Wen-Shan Chen, Senior Member, IEEE, and
} Chien-Hsiang Huang

\begin{abstract}
A novel printed monopole antenna with dual widebands is presented for simultaneously satisfying wireless local area network (WLAN) and worldwide interoperability for microwave access (WiMAX) applications. The antenna structure consists of a rectangular monopole with a microstrip feedline for excitation and a trapezoid conductor-backed plane for band broadening. The measured $10 \mathrm{~dB}$ bandwidth for return loss is from 2.01 to 4.27 GHz and 5.06 to 6.79 GHz, covering all the 2.4/5.2/5.8 GHz WLAN bands and 2.5/3.5/5.5 GHz WiMAX bands.
\end{abstract}

Index Terms-Dual-band antennas, monopole antennas, WiMAX antennas, WLAN antennas.

\section{INTRODUCTION}

$\mathbf{T}$ HE multiband or broadband antennas have aroused high interest in recent years for application to multimode communication systems. Because of low cost and process simplicity, printed monopole antennas are very popular candidates for these applications. The currently popular designs suitable for wireless local area network (WLAN) operation in the $2.4 \mathrm{GHz}(2.4-2.484 \mathrm{GHz})$ and $5.2 / 5.8 \mathrm{GHz}(5.15-5.35 \mathrm{GHz} /$ $5.725-5.825 \mathrm{GHz}$ ) bands have been reported in [1]-[8]. The key design configurations in order to meet this dual-band operation include a monopole antenna fed with a meandered coplanar waveguide (CPW) [1], a CPW-fed monopole antenna with two resonant paths [2], a CPW-fed tapered bent folded monopole antenna [3], a microstrip-fed double-T monopole antenna [4], a meander-line monopole antenna with a backed microstrip line [5], a C-shaped monopole antenna with a shorted parasitic element [6], and a branched monopole antenna with a truncated ground plane [7]. However, to further support the worldwide interoperability for microwave access (WiMAX) applications, none of the above available designs can achieve a dual-band response with sufficiently large bandwidth to additionally cover the $2.5 / 3.5 / 5.5 \mathrm{GHz}(2500-2690 / 3400-3690 / 5250-5850 \mathrm{MHz})$ WiMAX bands [9]. In [8], the authors presented a microstrip-fed crisscross monopole antenna with a square conductor-backed plane for dual-band WLAN applications. This design generally needs to consider many dimension parameters and the resulting

Manuscript received October 17, 2006; revised January 12, 2007. This work was supported in part by the Ministry of Education under Program of Aim for the Top University Plan, Taiwan, R.O.C., and by the National Science Council, Taiwan, R.O.C., by Grant 95-2221-E-110-027.

C.-Y. Pan, T.-S. Horng, and C.-H. Huang are with the Department of Electrical Engineering, National Sun Yat-Sen University, Kaohsiung 804, Taiwan, R.O.C. (e-mail: d8831816@student.nsysu.edu.tw).

W.-S. Chen is with the Department of Electronic Engineering, Southern Taiwan University of Technology, Tainan 710, Taiwan, R.O.C. (e-mail: chenws@mail.stut.edu.tw).

Digital Object Identifier 10.1109/LAWP.2007.891957

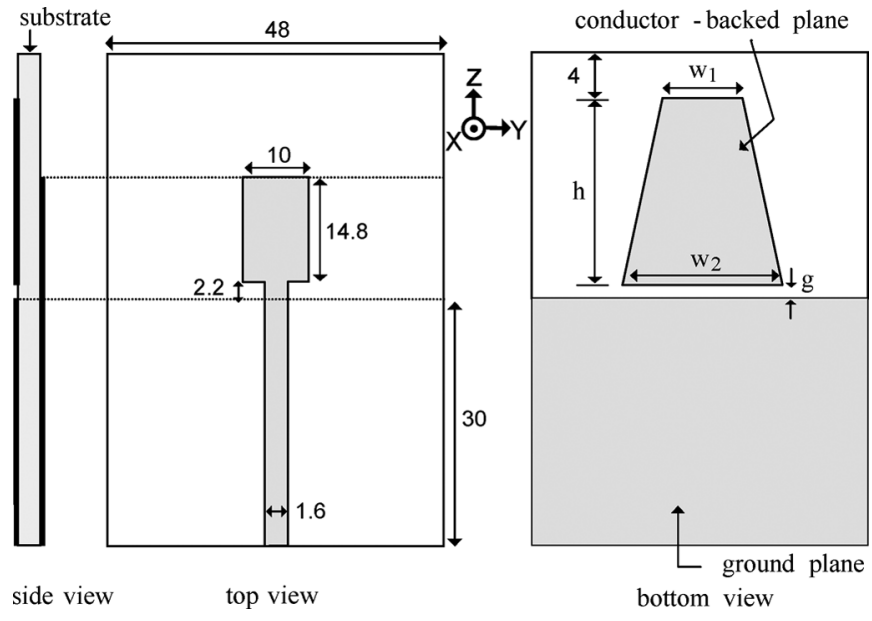

Fig. 1. Geometry of the proposed printed monopole antenna with dimensions in $\mathrm{mm}$.

bandwidth is still not sufficient to cover the $3.5 \mathrm{GHz}$ WiMAX bands. In this letter, a new antenna is proposed for the purpose of WLAN/WiMAX dual-mode operation. As illustrated in Fig. 1, the antenna is originally designed as a rectangular monopole fed by a $50-\Omega$ microstrip line. A metallic plate of trapezoid shape is placed under the rectangular monopole to perturb the resonant responses. This way, the antenna can achieve a dual wideband performance to simultaneously cover the most commonly used WLAN and WiMAX bands. This letter also provides detailed antenna dimensions and comparisons between simulated and measured results.

\section{Antenna Design AND Simulation}

Fig. 1 illustrates the geometry of the proposed dual wideband antenna for WLAN/WiMAX dual-mode operation. The antenna was implemented on an inexpensive FR4 substrate with thickness of $0.8 \mathrm{~mm}$ and relative permittivity of 4.4 . It can be seen from Fig. 1 that the rectangular monopole and $50 \Omega$ microstrip feedline are printed on the top side of substrate, while a trapezoid conducting plane and a semiground plane placed under the rectangular monopole and the microstrip feedline, respectively, are printed on the bottom side of substrate. The antenna performance is analyzed using high-frequency structure simulator (HFSS). In the proposed antenna configuration, the rectangular monopole can provide the fundamental and next higher resonant radiation band at 3.2 and $7.3 \mathrm{GHz}$, respectively, in the absence of the trapezoid conductor-backed plane. The trapezoid conductor backed plane can be regarded as a parasitic resonator electrically 


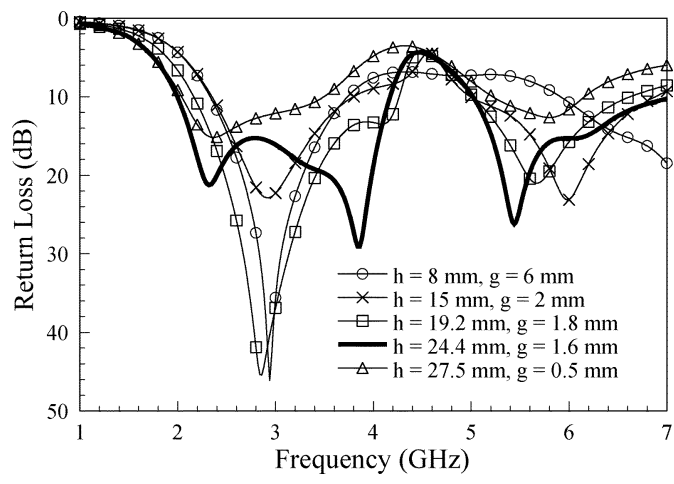

Fig. 2. Simulated return losses for the proposed antenna with varying dimensions of $\mathrm{h}$ and $\mathrm{g}$. $\left(\mathrm{w}_{1}=12 \mathrm{~mm}, \mathrm{w}_{2}=17 \mathrm{~mm}\right)$.

TABLE I

SIMULATED 10-dB BAND FREQUENCY RANGES AND BANDWIDTH FOR THE PROPOSED ANTENNA WiTH VARYING DIMENSIONS OF $\mathrm{w}_{1}$ AND $\mathrm{w}_{2}$ $(\mathrm{h}=24.4 \mathrm{~mm}, \mathrm{~g}=1.6 \mathrm{~mm})$

\begin{tabular}{ccc}
\hline \hline $\mathrm{w}_{1}, \mathrm{w}_{2}(\mathrm{~mm})$ & $\begin{array}{c}\text { Band 1 freq. range } \\
\text { and BW }(\mathrm{GHz})\end{array}$ & $\begin{array}{c}\text { Band 2 freq. range } \\
\text { and BW }(\mathrm{GHz})\end{array}$ \\
\hline 4,17 & $2.08-4.14,2.06$ & $5.18-6.90,1.72$ \\
12,17 & $2.00-4.16,2.16$ & $5.02-7.03,2.01$ \\
16,17 & $1.94-4.18,2.24$ & $4.96-6.94,1.98$ \\
12,11 & $1.94-3.35,1.41$ & $5.34-8.30,2.96$ \\
12,22 & $2.04-4.15,2.11$ & $4.97-5.71,0.74$ \\
\hline \hline
\end{tabular}

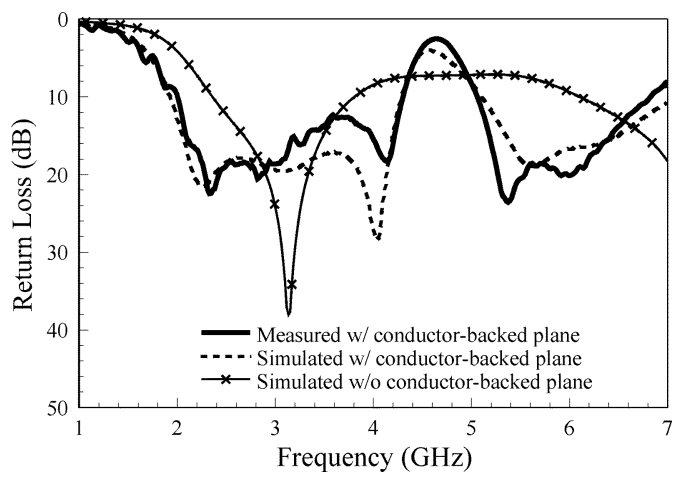

Fig. 3. Comparison between measured and simulated return losses for the proposed antenna. $\left(\mathrm{h}=24.4 \mathrm{~mm}, \mathrm{~g}=1.6 \mathrm{~mm}, \mathrm{w}_{1}=12 \mathrm{~mm}, \mathrm{w}_{2}=17 \mathrm{~mm}\right)$.

coupled to the rectangular monopole. By properly tuning the dimensions ( $h, \mathrm{w}_{1}$, and $\mathrm{w}_{2}$ ) and spacing $(\mathrm{g})$ to semiground plane for the trapezoid conductor backed plane, the antenna can create the second resonant frequency in individual resonant radiation band based on an over-coupling condition. This mechanism can remarkably increase the resonant radiation bandwidth. Fig. 2 shows the simulated return losses for the proposed antenna with varying $\mathrm{h}$ and $\mathrm{g}$. It is empirically found that band broadening can be optimized with choosing the dimensions: $\mathrm{h}=24.4 \mathrm{~mm}$ and $\mathrm{g}=1.6 \mathrm{~mm}$. Similarly, the simulated results with varying $\mathrm{w}_{1}$ and $\mathrm{w}_{2}$ are summarized in Table I. It has been also found that $\mathrm{w}_{1}=12 \mathrm{~mm}$ and $\mathrm{w}_{2}=17 \mathrm{~mm}$ are the optimal dimensions.

\section{RESUltS AND DISCUSSION}

The simulated return losses for the proposed antenna with and without the trapezoid conductor-backed plane are shown in Fig. 3. One can compare to verify that the use of the trapezoid

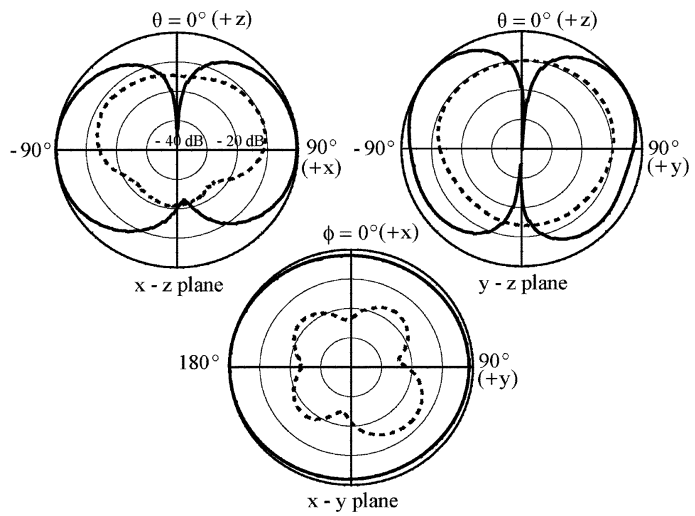

(a)

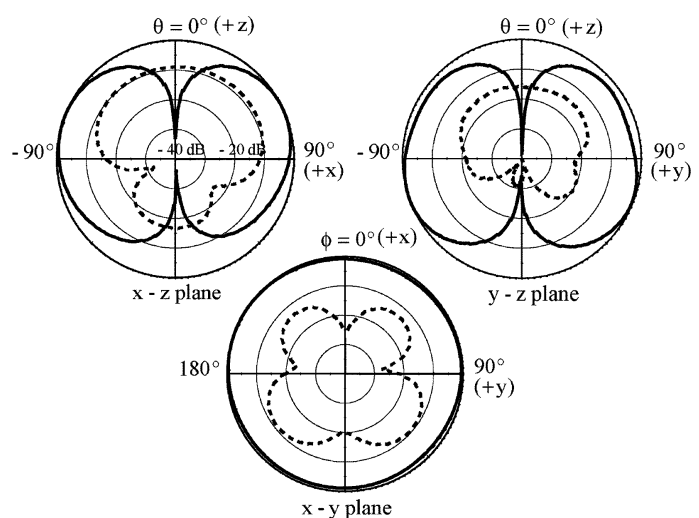

(b)

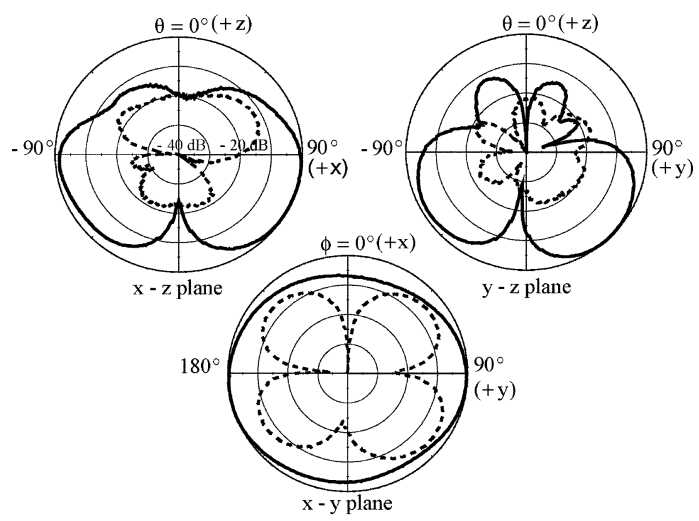

(c)

Fig. 4. Measured radiation patterns for the proposed antenna at (a) $2.5 \mathrm{GHz}$; (b) $3.5 \mathrm{GHz}$; and (c) $5.5 \mathrm{GHz} .\left(-\mathrm{E}_{\theta} \cdots \cdots \mathrm{E}_{\phi}\right)$.

conductor-backed plane can change impedance bandwidth of rectangular monopole for creating the dual widebands. Measured results for the antenna with the trapezoid conductor-backed plane are also provided in Fig. 3, showing a good agreement with simulated results. The 10-dB bandwidth of measured return loss reaches $2.26 \mathrm{GHz}(2.01-4.27 \mathrm{GHz})$ and $1.73 \mathrm{GHz}(5.06-6.79 \mathrm{GHz})$ in the lower and upper band, respectively, and can cover the $2.4-2.484 \mathrm{GHz}, 5.15-5.35$ $\mathrm{GHz}$, and 5.725-5.825 GHz WLAN bands, and the 2.5-2.69 $\mathrm{GHz}, 3.4-3.69 \mathrm{GHz}$, and 5.25-5.85 GHz WiMAX bands. The antenna polarizations in the above two widebands are vertical. The measured radiation patterns in the $x-y, x-z$, and $y-z$ plane are plotted in Fig. 4(a) to (c), respectively. From an overall view 


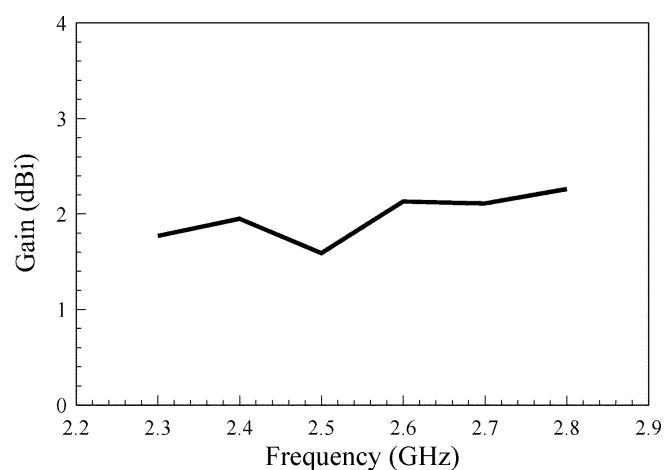

(a)

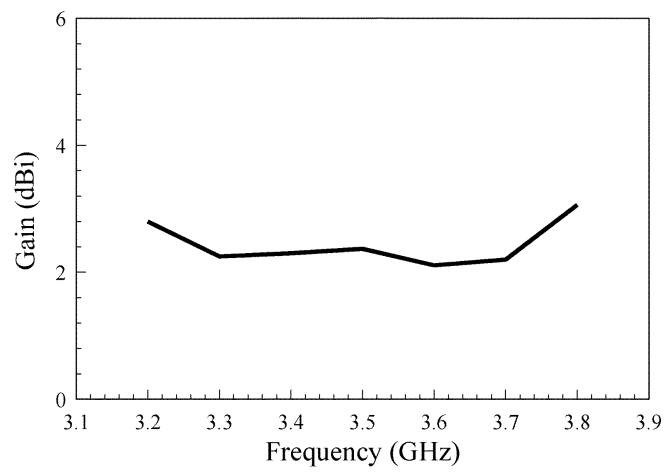

(b)

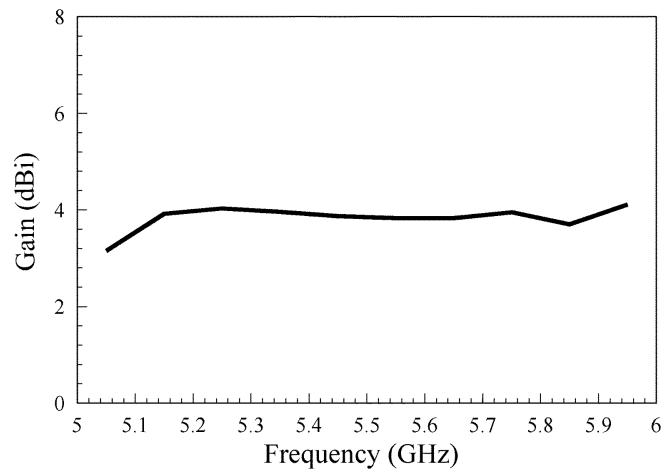

(c)

Fig. 5. Measured peak antenna gains against frequency for the proposed antenna in the (a) $2.3-2.8 \mathrm{GHz}$; (b) $3.2-3.8 \mathrm{GHz}$; and (c) $5.05-5.95 \mathrm{GHz}$ bands.

of these radiation patterns, the antenna behaves quite similarly to the typical printed monopoles. The H-plane patterns are almost omnidirectional in the lower band, alike to the ones at 2.5 and 3.5 GHz in Fig. 4(a) and (b), but appear more directional in the higher band, alike to the one at $5.5 \mathrm{GHz}$ in Fig. 4(c). This is because the trapezoid conductor-backed plane radiates more electromagnetic waves at higher frequencies so as to deteriorate the radiation patterns more significantly. The measured peak antenna gains against frequency in the range of $2.3-2.8 \mathrm{GHz}$, 3.2-3.8 GHz, and 5.05-5.95 GHz are plotted in Fig. 5(a) to (c), respectively, all showing small variations of less than $1 \mathrm{dBi}$.

\section{CONCLUSION}

A simple printed monopole antenna with a trapezoid conductor-backed plane for WLAN/WiMAX dual-mode operation has been presented. The use of trapezoid conductor-backed plane has increased impedance bandwidth very remarkably to sufficiently cover the $2.4 / 5.2 / 5.8 \mathrm{GHz}$ WLAN bands and 2.5/3.5/5.5 GHz WiMAX bands. The final measured results show satisfactory performance and good agreement with the simulated results.

\section{REFERENCES}

[1] W. C. Liu and W. R. Chen, "CPW-fed compact meandered patch antenna for dual-band operation," Electron. Lett., vol. 40, no. 18, pp. 1094-1095, Sep. 2004.

[2] T. H. Kim and D. C. Park, "CPW-fed compact monopole antenna for dual-band WLAN applications," Electron. Lett., vol. 41, no. 6, pp. 292-293, Mar. 2005.

[3] Y.-D. Lin and P.-L. Chi, "Tapered bent folded monopole for dual-band wireless local area network (WLAN) systems," IEEE Antenna Wireless Propag. Lett., vol. 4, pp. 355-357, 2005.

[4] Y.-L. Kuo and K.-L. Wong, "Printed double-T monopole antenna for 2.4/5.2 GHz dual-band WLAN operations," IEEE Trans. Antennas Propag., vol. 51, no. 9, pp. 2187-2192, Sep. 2003.

[5] S. H. Choi, J. K. Park, S. K. Kim, and H. Y. S. Kim, "Design of dualband antenna for the ISM band using a backed microstrip line," Microw. Opt. Technol. Lett., vol. 41, no. 6, pp. 457-460, Jun. 2004.

[6] C.-Y. Huang and P.-Y. Chiu, "Dual-band monopole antenna with shorted parasitic element," Electron. Lett., vol. 41, no. 21, pp. 1154-1155, Oct. 2005.

[7] M. N. Suma, R. K. Raj, M. Joseph, P. C. Bybi, and P. Mohanan, "A compact dual band planar branched monopole antenna for DCS/2.4 GHz WLAN applications," IEEE Microw. Wireless Compon. Lett., vol. 16, no. 5, pp. 275-277, May 2006.

[8] C.-Y. Pan, C.-H Huang, and T.-S. Horng, "A novel printed monopole antenna with a square conductor-backed parasitic plane for dual-band WLAN applications," in Proc. IEEE Antennas Propag. Soc. Int. Symp. Dig., 2004, vol. 1, pp. 261-264.

[9] Deploying License-Exempt WiMAX Solutions Intel Corp. Santa Clara, CA, 2005 [Online]. Available: http://www.intel.com/netcomms/ technologies/wimax 